\title{
Isolated brachycephaly
}

\author{
INSERM
}

\section{Source}

INSERM. (1999). Orphanet: an online rare disease and orphan drug data base. Isolated brachycephaly. ORPHA:35099

Isolated brachycephaly is a relatively frequent nonsyndromic craniosynostosis consisting of premature fusion of both coronal sutures leading to skull deformity with a broad flat forehead and palpable coronal ridges. 